\title{
DESEMPENHO E PERFIL PLASMÁTICO DE VACAS LEITEIRAS ALIMENTADAS COM GRÃO DE SOJA INTEGRAL OU MOIIDO
}

\author{
PERFORMANCE AND PLASMA PROFILE OF DAIRY COWS FED FULL OR PROCESSED \\ WHOLE RAW SOYBEAN IN DIETS
}

\author{
Naves, A.B. ${ }^{1}$; Barletta, R.V.'; Gandra, J.R. ${ }^{2}$; Freitas Júnior, J.É. ${ }^{1}$; Verdurico, L.C. ${ }^{1}$; \\ Benevento, B.C. ${ }^{1}$; Mingoti, R.D. ${ }^{1}$ e Rennó, F.P. ${ }^{1 *}$
}

\begin{abstract}
'Departamento de Nutrição e Produção Animal. Faculdade de Medicina Veterinária e Zootecnia. Universidade de São Paulo-FMVZ/USP. São Paulo/SP. Brasil. *francisco.renno@usp.br

${ }^{2}$ Departamento de Zootecnia. Faculdade de Ciências Agrarias. Universidade Federal da Grande Dourados. Dourados. Mato Grosso do Sul. Brasil. jeffersongandra@gmail.com
\end{abstract}

\section{PalaVRas ChaVES ADICIONAIS}

Composição do leite. Metabolismo.

\section{RESUMO}

O objetivo deste estudo foi avaliar os efeitos de diferentes formas de utilização de grão de soja integral e moído em diferentes peneiras e seus efeitos sobre o consumo de matéria seca, produção e composição do leite e os parâmetros sanguíneos. Foram utilizadas 12 vacas da raça Holandesa, agrupadas em três quadrados latinos balanceados $4 \times 4$, alimentadas com as seguintes rações: 1) controle (C); 2) grão de soja integral (Gl); 3) grão de soja moído 2 mm (G2), e 4) grão de soja moído $4 \mathrm{~mm}$ (G4). Houve redução no consumo de matéria seca em vacas suplementadas com as rações contendo grão de soja integral ou moído em relação à ração controle. Os parâmetros de produção e composição do leite, não foram influenciados pelas dietas experimentais. Não houve efeito das dietas fornecidas para as vacas sobre as concentrações dos parâmetros sanguíneos, glicose, ureia, nitrogênio ureico no soro (NUS), proteína total, albumina e as enzimas hepaticas aspartato aminotranferase (AST) e gama glutamil transferase (GGT) exceto para colesterol total e colesterol-HDL. O processamento do grão de soja cru não alterou o desempenho produtivo e o perfil plasmático de vacas leiteiras no terço médio de lactação.

\section{SUMMARY}

The objective of this study was to evaluate the

\section{Additional KEYWORdS}

Metabolism. Milk composition.

effects of different forms of use of processed or full whole raw soybean in different ground of screens and their effects on dry matter intake, milk yield and composition and blood parameters. Twelve Holstein cows were grouped in three balanced $4 \times 4$ Latin squares and fed the following diets: 1) control (C), 2) whole raw soybean (Gl), 3) ground soybean $2 \mathrm{~mm}$ (G2) and 4) ground soybean $4 \mathrm{~mm}$ (G4). A reduction in dry matter intake in cows fed diets containing whole raw soybean or ground in relation to the control diet. The parameters of production and milk composition were not affected by the experimental diets. There was no effect of diets for cows on concentrations of blood parameters, glucose, urea, blood urea nitrogen (NUS), total protein, albumin and hepatic enzymes aminotranferase aspartate (AST) and gamma glutamyl transferase (GGT) except for total cholesterol and HDL-cholesterol. The processing of whole raw soybean did not affect the performance and plasma profile of midlactation dairy cows.

\section{INTRODUÇÃO}

A soja é um grão rico em proteínas, cultivado em todo mundo como fonte de alimento para humanos e animais, e pertence à família Fabaceae. Destaca-se entre os alimentos proteicos de origem vegetal como 
fonte alternativa de proteína e energia, sendo considerada semente de oleaginosa mais disponível no mundo, podendo ser usada na alimentação dos ruminantes na sua forma original (crua) ou processada (Corrêa, 2007). Quanto ao custo, isso poderia acarretar vantagem econômica, pois em regiões produtoras brasileiras, na maioria das vezes, o preço do grão de soja é menor que o do farelo de soja.

Entre as características nutritivas da soja integral importantes na nutrição de ruminantes destaca-se a grande quantidade de proteína degradável no rúmen (PDR), que pode ser convertida em proteína não degradada no rúmen (PNDR) por meio de tratamento térmico, e ao seu elevado teor de energia devido ao teor de extrato etéreo. As sementes de oleaginosas se destacam por apresentar alto conteúdo de ácidos graxos poli-insaturados. O ácido linoléico (C18:2) predomina nas fontes mais comuns, sendo que a soja apresenta maiores concentrações de ácido linoléico (C18:2) (Dhiman et al. 2005).

Barletta et al. (2012) avaliaram a inclusão de diferentes níveis de grão de soja cru e integral $(0,8,16$ e $24 \%$ na MS total da dieta) na dieta de vacas leiteiras no terço inicial de lactação com média de produção de 31,21 $\mathrm{kg}$ /dia. Os autores não observaram efeitos sobre a produção de leite, teores de proteína, lactose, observando uma tendência no aumento dos teores de gordura para as dietas suplementadas com grão de soja e somente observaram diminuição do consumo da dieta com inclusão de $24 \%$ de grão de soja, não sendo observado sobre a digestibilidade da matéria seca. No presente estudo os autores recomendam o uso da inclusão $16 \%$ de grão de soja cru e integral na dieta de vacas leiteiras, com média de $30 \mathrm{~kg} / \mathrm{dia}$, com silagem de milho como volumosa base.

Tendo em vista a versatilidade e imensa utilização da soja grão em dietas de vacas leiteiras o objetivo deste trabalho foi avaliar utilização de grão de soja integral e moído em diferentes peneiras e seus efeitos sobre o consumo de matéria seca, produção e composição do leite e os parâmetros sanguíneos.

\section{MATERIALE MÉTODOS}

O experimento foi conduzido nas dependências do Laboratório de Pesquisa em Bovinos de Leite da Faculdade de Medicina Veterinária e Zootecnia da Universidade de São Paulo, Campus de Pirassununga, no período de 19 de agosto a 10 de novembro de 2009. Foram utilizadas 12 vacas da raça holandesa, com lactação média inicial de $121 \pm 79$, foram agrupadas em três quadrados latinos $4 \times 4$, contemporâneos e balanceados de acordo com o período de lactação, com duração de 21 dias cada um, sendo os 14 primeiros dias de adaptação às rações e os demais para avaliar as variáveis mensuradas. Os animais foram alimentados com quatro rações experimentais, formuladas para serem isonitrogenadas, de forma a atenderem as exigências nutricionais de vacas em lactação com aproximadamente $580 \mathrm{~kg}$ de peso corporal, 12 semanas de lactação, produzindo diariamente $30 \mathrm{~kg}$ de leite com 3,5\% de gordura, conforme recomendações do NRC (2001).

Os animais foram distribuídos aleatoriamente para receber as seguintes rações experimentais: 1) Controle (C), composto por ração sem a inclusão de grão de soja; 2) Grão de soja integral (GI); 3 ) Grão de soja moído 2 mm (G2) e 4) Grão de soja moído 4 $\mathrm{mm}$ (G4). Nas rações GI, G2 e G4 foram utilizados $20 \%$ de grão de soja na material seca, respectivamente, na forma de grão de soja integral, grão de soja moído em peneira de $2 \mathrm{~mm}$ e em peneira de $4 \mathrm{~mm}$. Durante o período experimental foi utilizada a silagem de milho como volumoso, e as respectivas rações e água foram fornecidos ad libitum. Diariamente foram feitas pesagens das quantidades dos volumosos e concentrados fornecidos e das sobras de cada tratamento, para estimativa do consumo.

Os animais foram arraçoados de acordo 


\section{ALIMENTAÇÃO DE VACAS LEITEIRAS COM GRÃO DE SOJA INTEGRAL E MOÍDO}

com o consumo de matéria seca no dia anterior, de forma a ser mantido um percentual de sobras das rações, diariamente, entre 5 e $10 \%$ do fornecido para não haver limitação de consumo. Após o preparo da mistura no cocho, as amostras dos alimentos fornecidos foram coletadas e armazenadas a -20 ${ }^{\circ} \mathrm{C}$. Posteriormente foram realizadas análises químico-bromatológicas nas amostras armazenadas. As coletas das amostras foram realizadas ao final de cada período experimental, após o período de adaptação as rações (tabelas I e II).

Nas amostras de sobras e alimentos fornecidos foram determinados os teores de matéria seca (MS), matéria orgânica, cinzas, extrato etéreo, o nitrogênio insolúvel em detergente neutro, nitrogênio insolúvel em detergente ácido e lignina de acordo com as metodologias descritas por AOAC (2000). $\mathrm{O}$ teor de proteína bruta foi obtido pela

Tabela I. Ingredientes do concentrado (\% $M S)$. (Ingredients of the concentrate (\% DM)).

\begin{tabular}{lcccc}
\hline & \multicolumn{4}{c}{ Concentrados } \\
& C & Gl & G2 & G4 \\
\hline Milho moído & 54,48 & 37,69 & 37,69 & 37,69 \\
Farelo de soja & 37,76 & 15,18 & 15,18 & 15,18 \\
Grão de soja & - & 40,55 & 40,55 & 40,55 \\
Uréia pecuária & 1,04 & - & - & - \\
Sulfato de amônia & 0,20 & - & - & - \\
Bicarbonato de sódio & 1,60 & 1,62 & 1,62 & 1,62 \\
Óxido de magnésio & 0,18 & 0,18 & 0,18 & 0,18 \\
Mistura mineral ${ }^{1}$ & 3,97 & 4,01 & 4,01 & 4,01 \\
Calcáreo & 0,28 & 0,28 & 0,28 & 0,28 \\
Sal comum & 0,48 & 0,49 & 0,49 & 0,49 \\
& & & & \\
\hline
\end{tabular}

$\mathrm{C}=$ controle $; \mathrm{Gl}=$ grão de soja integral, $20 \% \mathrm{MS}$ G2= grão de soja moído em peneira de $2 \mathrm{~mm}, 20 \%$ MS; G4= grão de soja moído em peneira de $4 \mathrm{~mm}$, $20 \%$ MS.

${ }^{1}$ Composição por quilograma de produto: cálcio, $190 \mathrm{~g}$; fósforo, $73 \mathrm{~g}$; enxofre, $30 \mathrm{~g}$; magnésio, 44 g; cobre, 340 mg; zinco, 1350 mg; manganês, 940 $\mathrm{mg}$; cobalto, $3 \mathrm{mg}$; iodo, $16 \mathrm{mg}$; selênio, $10 \mathrm{mg}$; ferro, $1064 \mathrm{mg}$; vitamina A, 100 000Ul; vitamina D 40 000Ul; vitamina E 600Ul.
Tabela II. Composição das rações (C, GI G2, G4). (Composition of diets).

\begin{tabular}{lcccc}
\hline & $\mathrm{C}$ & $\mathrm{Gl}$ & $\mathrm{G} 2$ & $\mathrm{G} 4$ \\
\hline Ingredientes (\%) & & & & \\
Milho moído & 27,17 & 18,60 & 18,60 & 18,60 \\
Farelo de soja & 18,83 & 7,49 & 7,49 & 7,49 \\
Grão de soja integral & - & 20,01 & 20,01 & 20,01 \\
Uréia pecuária & 0,52 & - & - & - \\
Sulfato de amônia & 0,10 & - & - & - \\
Bicarbonato de sódio & 0,80 & 0,80 & 0,80 & 0,80 \\
Óxido de magnésio & 0,09 & 0,09 & 0,09 & 0,09 \\
Mistura mineral $^{1}$ & 1,98 & 1,98 & 1,98 & 1,98 \\
Calcáreo & 0,14 & 0,14 & 0,14 & 0,14 \\
Sal comum & 0,24 & 0,24 & 0,24 & 0,24 \\
Silagem de milho & 49,87 & 49,35 & 49,35 & 49,35
\end{tabular}

Composição bromatológica

$\begin{array}{lllll}\text { MS }^{2} & 62,67 & 63,27 & 63,27 & 63,27\end{array}$

$\begin{array}{lllll}\mathrm{MO}^{3} & 91,51 & 91,98 & 91,98 & 91,98\end{array}$

$\begin{array}{lllll}\mathrm{PB}^{3} & 17,45 & 17,18 & 17,18 & 17,18\end{array}$

$\begin{array}{lllll}\text { NIDN }^{4} & 21,55 & 22,18 & 22,09 & 22,57\end{array}$

$\begin{array}{lllll}\text { NIDA }^{4} & 16,34 & 15,81 & 15,81 & 15,81\end{array}$

$\begin{array}{lllll}\mathrm{EE}^{3} & 2,49 & 6,42 & 6,42 & 6,42\end{array}$

$\begin{array}{lllll}\mathrm{CT}^{3} & 71,82 & 75,37 & 75,37 & 75,37\end{array}$

$\begin{array}{lllll}\text { FDN }^{3} & 33,86 & 36,08 & 36,08 & 36,08\end{array}$

$\begin{array}{lllll}\text { CNF }^{3} & 37,96 & 32,54 & 32,54 & 32,54\end{array}$

$\begin{array}{lllll}\text { FDA }^{3} & 24,16 & 24,04 & 24,04 & 24,04\end{array}$

$\begin{array}{lllll}\text { Lignina }^{3} & 4,29 & 4,70 & 4,70 & 4,70\end{array}$

$\begin{array}{lllll}\text { MM }^{3} & 8,24 & 7,77 & 7,77 & 7,77\end{array}$

$\begin{array}{lllll}\text { NDT }^{5} & 69,55 & 73,38 & 73,54 & 73,53\end{array}$

$\begin{array}{lllll}\mathrm{EL}_{1}{ }^{5}(\mathrm{Mcal} / \mathrm{kg}) & 1,62 & 1,75 & 1,75 & 1,75\end{array}$

$\mathrm{C}=$ controle $; \mathrm{Gl}=$ grão de soja integral; $\mathrm{G} 2=$ grão de soja moído ( $2 \mathrm{~mm})$; G4= grão de soja moído ( $4 \mathrm{~mm}$ ); $\mathrm{MS}=$ matéria seca; $\mathrm{MO}=$ matéria orgânica; $\mathrm{PB}=$ proteína bruta; NIDN= nitrogênio insolúvel em detergente neutro; NIDA = nitrogênio insolúvel em detergente ácido; $\mathrm{EE}=$ extrato etéreo; $\mathrm{CT}=$ carboidratos totais; FDN= fibra em detergente neutro; $\mathrm{CNF}=$ carboidratos não fibrosos; $\mathrm{FDA}=$ fibra em detergente ácido; $M M=$ matéria mineral; $\mathrm{NDT}=$ nutrientes digestíveis totais; $\mathrm{EL}_{\mathrm{l}}=$ energia líquida de lactação.

${ }^{1}$ Composição por kg: Ca 190 g; P 73 g; S 30 g; Mg 44 g; Cu 340 mg; Zn 1350 mg; Mn 940 mg; Co 3 mg; 116 mg; Se10 mg; Fe1064 mg; vitamina A 100 000; vitamina $D 40000$, vitamina $E 600,0 .{ }^{2}$ porcentagem da matéria natural. ${ }^{3}$ porcentagem da MS. ${ }^{4}$ porcentagem $\mathrm{N}$ total. ${ }^{5}$ equações do NRC (2001). 
multiplicação do teor de nitrogênio total por 6,25 . Os teores de fibra detergente neutro e fibra detergente ácido foram obtidos conforme método descrito por Van Soest e Mason (1991), utilizando-se $\alpha$-amilase e sem adição de sulfito de sódio na determinação do FDN.

Os teores de carboidratos totais (CT) foram calculados segundo Sniffen et al. (1992), de carboidratos não-fibrosos (CNF), de acordo com Hall (1998), energia líquida de lactação (ELL), segundo o NRC (2001) e nutrientes digestíveis totais (NDT), segundo Weiss et al. (1992):

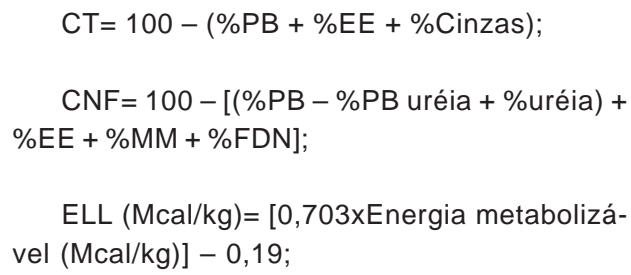

ELL $(\mathrm{Mcal} / \mathrm{kg})=[0,703 \times$ Energia metabolizável $(\mathrm{Mcal} / \mathrm{kg})]-0,19$;

$\mathrm{NDT}(\%)=\mathrm{PBD}+\mathrm{FDND}+\mathrm{CNFD}+(\mathrm{EED} \times 2,25)$.

em que:

$\mathrm{PBD}=$ proteína bruta digestível;

FDND = fibra em detergente neutro digestível; $\mathrm{CNFD}=$ carboidratos não-fibrosos digestíveis; $\mathrm{EED}=$ extrato etéreo digestível.

As vacas foram ordenhadas mecanicamente duas vezes ao dia, as 6:30 e as 15:30 horas, sendo a produção de leite registrada diariamente durante todo o período experimental. A produção de leite foi corrigida para 3,5\% de gordura (PLC) segundo fórmula de Sklan et al. (1992) onde:

$\mathrm{PLC}=\left(0,432+0,1625^{\star}\right.$ teor de gordura do leite) ${ }^{*} \mathrm{~kg}$ de leite

As coletas de leite foram realizadas no entre o 24 e o 26 dia de cada período experimental duas vezes ao dia no momento das ordenhas, sendo homogeneizadas e analisadas no mesmo dia, para a obtenção dos dados foram realizadas médias aritméticas dos 3 dias de análises. As análises de proteína, gordura e lactose foram realizadas pelo (Lactoscan Milk Analyzer®).

Para determinação da ureia e NUL (nitrogênio ureico no leite), as amostras de leite foram desproteinizadas. As análises da concentração de ureia no leite desproteinizado foram realizadas no, por meio de kits comerciais (Laborlab® e CELM $®$ ). A concentração de nitrogênio uréico no leite foi determinada indiretamente por meio da seguinte fórmula:

Nitrogênio uréico= uréia $(\mathrm{mg} / \mathrm{dL}) / 2,14$

As coletas de sangue foram realizadas no $19^{\circ}$ dia de cada período experimental por punção da veia e/ou artéria coccígea, anteriormente ao fornecimento das rações no período da manhã. As amostras foram coletadas em tubos vacuolizados (vacutainer) de $10 \mathrm{~mL}$ para dosagem dos parâmetros sanguíneos glicose, colesterol total, colesterol-HDL, proteínas totais, albumina, uréia e NUS (nitrogênio uréico no sangue), as enzimas aspartato aminotransferase (AST) gama glutamil transferase (GGT) no soro, e tubos contendo fluoreto de sódio para dosagem de glicose no plasma.

Imediatamente após coleta as amostras foram coletadas refrigeradas e centrifugadas a 2000 x g durante 15 minutos, para a separação do soro ou plasma. O centrifugado obtido foi transferido para tubetes plásticos, identificados e armazenados a $-20^{\circ} \mathrm{C}$, até o procedimento das análises laboratoriais, onde foram analisados e expressos a $30^{\circ} \mathrm{C}$.

As análises das concentrações dos parâmetros sanguíneos foram realizadas, por meio de kits comerciais (Laborlab $\AA$ e Celm $\AA$ ) que utilizam método enzimático colorimétrico de ponto final, sendo a leitura realizada em analisador automático de bioquímica sanguínea (sistema de bioquímica automático sba-200 Celm®).

Os dados obtidos foram submetidos ao SAS (2004), verificando a normalidade dos 


\section{ALIMENTAÇÃO DE VACAS LEITEIRAS COM GRÃO DE SOJA INTEGRAL E MOÍDO}

resíduos e a homogeneidade das variâncias pelo proc univariate.

Os dados foram analisados, pelo proc mixed de acordo com a seguinte modelo:

$Y_{i j k y}=\mu+q i+a j+p y+t k+$ eijyk

onde:

$\mathrm{Y}_{\mathrm{ijyk}}=$ variável dependente;

$\mu=$ media geral;

$q i=$ efeito de quadrado ( $i=1$ to 3$)$;

$\mathrm{aj}=$ efeito de animal ( $\mathrm{j}=1$ to 12$)$;

$\mathrm{py}=$ efeito do período $(\mathrm{y}=1$ to 4$)$;

$\mathrm{tk}=$ efeito do tratamento $(\mathrm{k}=1$ to 4$)$;

eijk= erro;

Efeito aleatório aj.py= animal e período.

Os graus de liberdade calculados foram realizados de acordo com o método satterthwaite.

Os dados obtidos foram analisados por contrastes ortogonais, sendo: contraste $\mathrm{c} 1=$ controle vs. grão de soja; c2= grão de soja integral $v s$. grão de soja moído; c3= grão de soja moído $2 \mathrm{~mm} v s$. moído $4 \mathrm{~mm}$. Foi adotando nível de significância de $5 \%$.

\section{RESULTADOSEDISCUSSÃO}

Os resultados referentes ao consumo diário de matéria seca de acordo com as rações experimentais podem ser observados na tabela III. Quando foi avaliado o C1, os animais que receberam as rações contendo grão de soja apresentaram menor consumo de matéria seca $(p<0,05)$ em relação aos animais submetidos à dieta controle, entretanto não foi observado efeito no consumo dos animais submetidos às dietas com grão de soja integral ou moído em peneiras com crivos de 2 ou $4 \mathrm{~mm}$, demonstrando assim não haver necessidade de nenhuma forma de processamento do grão de soja cru para sua utilização na alimentação de vacas de leite.

Os resultados obtidos para o consumo de matéria seca reforçam que a forma de processamento do grão não interfere na fisiologia regulatória do consumo de nutrientes o que observado na tabela III foi somente o efeito de regulação do consumo proporcionada pela inclusão de fontes de lipídios nas dietas visto que a inclusão de $20 \%$ de grão de soja cru e integral proporcionou um teor de $6,42 \%$ de extrato etéreo nas dietas (tabela II). A redução do consumo observada das dietas suplementadas com grão de soja em relação à dieta controle foi de $1 \mathrm{~kg}$ de matéria seca por dia. Entre as dietas suplementadas com grão de soja poderia se esperar um menor consumo pela dieta $\mathrm{G} 4$, onde a maior exposição da matriz do grão poderia aumentar a concentração de lipídios livres no rumem, o que não foi observado no consumo de matéria seca.

Barletta et al. (2012), utilizaram rações contento 8,16 e $24 \%$ de inclusão de grão de soja cru e integral na matéria seca da dieta de vacas de leite com média de produção de $30 \mathrm{~kg} / \mathrm{leite} /$ dia e utilizando silagem de milho como volumoso, observaram que apenas os animais submetidos a dieta com $24 \%$ de inclusão de grão de soja apresentaram diminuição no consumo de matéria seca, entretanto os autores descrevem que a dieta apresentava mais de $7 \%$ de extrato etéreo o que explicaria no menor consumo de matéria seca, evidenciando assim os benefícios de utilização do grão de soja cru e integral na alimentação de vacas de leite.

Rabello et al. (1996) em estudo com quatro vacas 7/8 holandês-zebu em lactação, com fístula no rúmen e abomaso, testou quatro níveis de inclusão de grão de soja moído, e não observaram efeito no consumo de matéria seca. Mohamed et al. (1988), concluíram que o grão de soja cru ou tostado com inclusão de $20 \%$ na MS da dieta, diminuiu o consumo.

Deresz et al. (1996), utilizaram vacas em início de lactação e com média de produção de leite de 28,0 kg/dia, incluíram 0, 12 e $24 \%$ de grão de soja cru na matéria seca da dieta, e utilizaram silagem de milho como volumoso em uma relação $\mathrm{V} / \mathrm{C}$ de $60: 40$, os autores não encontraram diferença no consumo de matéria seca entre as dietas experimentais, 


\section{NAVES ETAL.}

e os resultados de consumo são próximos dos encontrados neste estudo.

Não houve efeito $(p>0,05)$ das rações experimentais sobre a produção de leite, produção de leite corrigida, teor e produção de gordura, proteína e lactose (tabela III). Estes resultados indicam que a inclusão de $20 \%$ de grão de soja integral ou moído não influenciou o aporte de nutrientes para a glândula mamária, pois foi obtido similar desempenho produtivo.

$\mathrm{Na}$ avaliação do contraste $\mathrm{C} 2$, grão de soja integral vs. moído, não foi observado melhoria $(p>0,05)$ do desempenho produtivo quando o grão de soja foi utilizado na forma integral ou moído. Além disso, quando avaliado o desempenho das vacas submetidas ao grão de soja moído na peneira de 2 $\mathrm{mm}$ vs. de $4 \mathrm{~mm}$ (C3), também não houve diferença $(p>0,05)$ nos resultados.

Em relação às concentrações de ureia e NUL (nitrogênio ureico no leite) no leite foi observado efeito $(\mathrm{p}<0,05)$ quando se comparou a ração com o grão de soja inteiro com as rações com o grão de soja moído, obtendo-se maiores concentrações para rações com o grão moído, esses resultados podem ser explicados pela maior absorção e degradação e consequente metabolismo do grão moído no rúmen, pois o grão inteiro apresenta uma proteção natural da fibra que envolve a matriz de nutriente e também pela menor superfície de contato em relação ao grão processado, fazendo com que seja degradado lentamente no rúmen.

A concentração de nitrogênio no leite em forma de ureia esta positivamente correlacionada com a concentração de ureia

Tabela III. Consumo, desempenho produtivo e composição do leite em função das rações experimentais. (Intake, productive performance and milk composition according to the experimental diets).

\begin{tabular}{|c|c|c|c|c|c|c|c|c|c|}
\hline \multirow[t]{2}{*}{ Variável } & \multicolumn{4}{|c|}{ Rações } & \multirow[b]{2}{*}{ Média } & \multirow[b]{2}{*}{ EPM } & \multicolumn{3}{|c|}{ Contrastes } \\
\hline & C & Gl & G2 & G4 & & & C1 & C2 & C3 \\
\hline \multicolumn{10}{|l|}{ Consumo kg/dia } \\
\hline $\begin{array}{l}\text { Matéria seca } \\
\text { Produção kg/dia }\end{array}$ & 23,72 & 22,99 & 22,55 & 22,56 & 23,21 & 0,45 & 0,002 & 0,178 & 0,987 \\
\hline Leite & 31,80 & 30,17 & 31,49 & 30,81 & 31,07 & 0,54 & 0,065 & 0,076 & 0,279 \\
\hline 3,5\% PLC & 28,3 & 26,8 & 27,4 & 27,1 & 27,4 & 0,59 & 0,039 & 0,590 & 0,822 \\
\hline Gordura & 0,90 & 0,84 & 0,84 & 0,85 & 0,86 & 0,03 & 0,095 & 0,951 & 0,855 \\
\hline Proteína & 0,96 & 0,90 & 0,95 & 0,92 & 0,93 & 0,01 & 0,156 & 0,206 & 0,460 \\
\hline Lactose & 1,42 & 1,31 & 1,33 & 1,31 & 1,34 & 0,04 & 0,289 & 0,563 & 0,329 \\
\hline \multicolumn{10}{|l|}{ Composição do leite \% } \\
\hline Gordura & 2,89 & 2,85 & 2,67 & 2,75 & 2,79 & 0,10 & 0,252 & 0,246 & 0,564 \\
\hline Proteína & 3,08 & 3,05 & 3,02 & 3,05 & 3,05 & 0,02 & 0,364 & 0,722 & 0,685 \\
\hline Lactose & 4,46 & 4,35 & 4,23 & 4,34 & 4,35 & 0,03 & 0,897 & 0,564 & 0,489 \\
\hline \multicolumn{10}{|c|}{ Composição do leite mg/dL } \\
\hline Uréia & 38,93 & 35,87 & 42,29 & 42,46 & 40,19 & 0,64 & 0,673 & 0,042 & 0,960 \\
\hline NUL & 18,18 & 16,75 & 19,75 & 19,83 & 18,77 & 0,64 & 0,673 & 0,042 & 0,960 \\
\hline Peso corporal (kg) & 543,5 & 548,1 & 536,0 & 531,8 & 539,8 & 8,68 & 0,324 & 0,452 & 0,567 \\
\hline E ECC & 2,73 & 2,75 & 2,73 & 2,73 & 2,73 & 0,03 & 0,234 & 0,454 & 0,345 \\
\hline
\end{tabular}

$\mathrm{C}=$ controle; $\mathrm{Gl}=$ grão de soja integral, $20 \% \mathrm{MS} ; \mathrm{G} 2=$ grão de soja moído em peneira de $2 \mathrm{~mm}, 20 \% \mathrm{MS}$; G4= grão de soja moído em peneira de $4 \mathrm{~mm}, 20 \% \mathrm{MS}$; C1 = controle vs. com grão de soja (Gl+G2+G4); $\mathrm{C} 2=$ grão integral vs. grão de soja moído $(\mathrm{G} 2+\mathrm{G} 4) ; \mathrm{C} 3=$ grão de soja moído em peneira de $2 \mathrm{~mm}$ vs. grão de soja moído em peneira de $4 \mathrm{~mm}$. E ECC= escore de condição corporal. 


\section{ALIMENTAÇÃO DE VACAS LEITEIRAS COM GRÃO DE SOJA INTEGRAL E MOÍDO}

sanguínea, ambas utilizadas como indicadores da correta utilização da proteína dietética, e os valores encontrados na tabela III demonstram níveis adequados, e dentro dos valores considerados corretos de uma dieta de vacas leiteiras com o nível de produção apresentado.

Segundo McDonald et al. (2002), não está claro o efeito deletério sobre o aproveitamento de nutrientes da utilização do grão de soja cru em ruminantes, especialmente para vacas em lactação. Porém, estes autores relataram que existe limite teórico de fornecimento de $2,3 \mathrm{~kg} / \mathrm{vaca} /$ dia de grão de soja cru. Esse limite foi baseado na presença de fatores anti-nutricionais, que poderiam reduzir o aproveitamento de nutrientes e o desempenho produtivo em rações com grão de soja cru. No presente estudo utilizou-se $20 \%$ de grão de soja cru na matéria seca das rações, na forma integral ou moído, que resultou no fornecimento de aproximadamente $5,2 \mathrm{~kg} / \mathrm{vaca} / \mathrm{dia}$ de grão de soja, sem, no entanto, apresentar alteração no desempenho produtivo dos animais.
O peso corporal e o escore de condição corporal não foram influenciados $(p>0,05)$ pelas rações experimentais (tabela III). Isso confirma que as rações atenderam as exigências nutricionais dos animais durante o período experimental.

As concentrações plasmáticas de glicose no soro, proteínas totais, aspartato aminotransferase (AST) e gama glutamil transferase (GGT) não foram influenciadas ( $>>0,05)$ pelas rações experimentais (tabela IV).

Os dados observados para a concentração das enzimas hepáticas e das proteínas totais estão dentro dos valores de referencia para vacas leiteiras (Kaneko et al., 1997). A dosagem destas enzimas hepáticas e das proteínas totais são importantes para o monitoramento do status metabólico de possíveis enfermidades causadas pela alta concentração de lipídios nas dietas bem como algum fator anti-nutricional que o grão de soja pudesse causar aos animais, o que não foi observado em nenhuma dieta suplementada com grão de soja. As concentra-

Tabela IV. Metabólitos plasmáticos em função das rações experimentais. (Plasma metabolites according to the experimental diets).

\begin{tabular}{lccccccccc}
\hline Variável & \multicolumn{4}{c}{ Tratamentos } & & & & \multicolumn{3}{c}{ Valores de p } \\
& C & G1 & G2 & G3 & Médias & EPM & C1 & C2 & C3 \\
\hline mg/dL & & & & & & & & & \\
$\quad$ Glicose & 65,77 & 63,58 & 61,25 & 62,89 & 63,35 & 1,12 & 0,059 & 0,381 & 0,413 \\
$\quad$ Colesterol total & 194,40 & 232,67 & 221,83 & 224,50 & 217,35 & 4,70 & 0,003 & 0,377 & 0,830 \\
$\quad$ Colesterol-HDL & 98,06 & 119,50 & 113,21 & 121,58 & 112,91 & 3,02 & 0,006 & 0,768 & 0,317 \\
$\quad$ Uréia & 40,04 & 34,58 & 38,08 & 41,70 & 38,58 & 1,18 & 0,466 & 0,048 & 0,258 \\
$\quad$ NUS & 18,71 & 16,15 & 17,80 & 19,48 & 18,03 & 0,55 & 0,465 & 0,043 & 0,253 \\
g/L & & & & & & & & & \\
$\quad$ Proteína total & 4,91 & 4,90 & 5,00 & 5,01 & 4,96 & 0,04 & 0,166 & 0,649 & 0,843 \\
$\quad$ Albumina & 2,08 & 1,99 & 2,16 & 2,09 & 2,08 & 0,02 & 0,138 & 0,050 & 0,547 \\
UI/L & & & & & & & & & \\
$\quad$ AST & 65,00 & 62,83 & 69,58 & 65,75 & 65,79 & 2,21 & 0,786 & 0,246 & 0,423 \\
$\quad$ GGT & 6,59 & 6,32 & 6,25 & 6,64 & 6,42 & 0,30 & 0,790 & 0,856 & 0,638 \\
\hline
\end{tabular}

$\mathrm{C}=$ controle; $\mathrm{G} 1=$ grão de soja integral; $\mathrm{G} 2=$ grão de soja $2 \mathrm{~mm}$; $\mathrm{G} 3=$ grão de soja $4 \mathrm{~mm} ; \mathrm{C} 1=$ controle vs. grão de soja $(\mathrm{C} 2+\mathrm{C} 3+\mathrm{C} 4) ; \mathrm{C} 2=$ grão de soja integral vs. grão de soja processado; $\mathrm{C} 3=$ grão de soja processado $2 \mathrm{~mm} v s$. grão de soja processado $4 \mathrm{~mm}$. 
ções de glicose não foram alteradas, mesmo com a maior concentração de carboidratos não fibrosos da dieta controle (tabela II) muito provavelmente porque o nível de produção de leite foi semelhante entre as dietas experimentais, alterações nas concentrações de glicose estão mais relacionadas em vacas leiteiras com o estágio de lactação dos animais.

Mesmo não sendo influenciada a concentração de glicose plasmática pelas rações experimentais, os resultados observados foram semelhante aos estudos de Elliott et al. (1993) e Bremmer et al. (1998), que verificaram variação na concentração de glicose plasmática em vacas suplementadas com diferentes fontes de gordura. A manutenção da concentração de glicose plasmática se relaciona à relativa estabilidade nas concentrações de glicose em ruminantes.

Oliveira et al. (2005) avaliaram a bioquímica sérica de vacas Holandesas no pré e pós-parto e observaram valores para as concentrações da enzima gama glutamiltransferase, de $13,54 \mathrm{mg} / \mathrm{dL}( \pm 4,26)$ aos 180 dias de lactação. Hoedemaker et al. (2004) avaliaram os parâmetros sanguíneos de 238 vacas e observaram valores da enzima aspartato aminotransferase de $40,0 \mathrm{U} / \mathrm{L}$ aos 77 dias pós-parto, valor este semelhante ao encontrado neste estudo.

As vacas que receberam as rações contendo grão de soja apresentaram maiores concentrações de colesterol total e colesterol-HDL $(\mathrm{p}<0,05)$ em relação à ração controle. Esses resultados estão de acordo com a porcentagem de extrato etéreo das rações contendo grão de soja e ao maior consumo consequientemente de ácidos graxos pelos animais submetidos a estas dietas, que proporcionou aumento das respectivas frações relativas ao metabolismo de lipídios transportado no sangue (tabela IV). O lipidograma das vacas suplementadas com grão de soja cru integral ou processado estão acima dos valores de referencia citados por (Kaneko et al., 1997), teores de extrato etéreo acima de $5 \%$ nas dietas proporcionam valores elevados de todas as frações do colesterol, principalmente se o perfil de ácidos graxos for predominantemente de ácidos insaturados como ômega 6.

Elliott et al. (1993), de forma semelhante, observaram aumento da concentração de colesterol total no sangue de vacas com cerca de 64 dias em lactação e suplementadas com diferentes fontes de gordura, com médias de 247 e $246 \mathrm{mg} / \mathrm{dL}$, respectivamente, para os níveis de 2,5 e 5,0\% de EE na dieta. De acordo com Schauff et al. (1992) e Elliott et al. (1993), este aumento da concentração de colesterol total no sangue ocorre devido à elevação da demanda energética necessária para digestão, absorção e transporte de ácidos graxos de cadeia longa ingerida advinda das fontes de gordura.

Bremmer etal. (1998) tambémobservaram aumento da concentração de colesterol total em vacas que receberam infusão de misturas de ácidos graxos de cadeia longa no abomaso, de forma semelhante à Christensen et al. (1994), que verificaram tendência de aumento da concentração de triglicerídeos em vacas que receberam misturas de ácidos graxos de cadeia longa no abomaso.

Em relação às concentrações de ureia, NUS (nitrogênio ureico no sangue) e albumina foi observado efeito para o $\mathrm{C} 2$ $(\mathrm{p}<0,05)$ quando foi comparada a ração contendo grão de soja integral às com grão de soja moído, onde os animais submetidos às dietas com o grão processado apresentaram maiores concentrações. Estes resultados estão intimamente relacionados aos apresentados para ureia e NUL (tabela III).

Geralmente, valores elevados de NUS estão associados a dietas com valores elevados de proteína degradável no rúmen (PDR) e com a concomitante deficiência de carboidratos não fibrosos no rúmen, o que impossibilita uma melhor utilização do nitrogênio como fonte de crescimento microbiano. O conseqüente aumento na concentração de amônia no rúmen resultaria 


\section{ALIMENTAÇÃO DE VACAS LEITEIRAS COM GRÃO DE SOJA INTEGRAL E MOÍDO}

em aumento na concentração deste metabólito no sangue e subsequente aumento na concentração de ureia sanguínea.

No entanto, quantidades elevadas de proteína não degradável no rúmen (PNDR) gera a mesma condição, pois excessos de nitrogênio, tanto de origem ruminal como pós-ruminal, são eliminados do organismo através do mesmo processo de síntese hepática de ureia. Assim, o excesso de proteína, tanto na forma não degradável como degradável, aumentará o NUS (Roseler et al., 1993).

\section{CONCLUSÃO}

A suplementação de $20 \%$ de grão de soja cru integral ou processado nas dietas alterou o perfil metabólico, principalmente o lipidograma, contudo não influenciou o

\section{BIBLIOGRAFIA}

AOAC. 2000. Official Methods of Analysis. $17^{\text {th }}$ ed AOAC Int. Gaithersburg, MD.

Barletta, R.V.; Rennó, F.P.; Gandra, J.R.; Freitas Junior, J.E.; Verdurico, L.C.; Mingoti, R.D. e Vilela, F.G. 2012. Desempenho produtivo e parâmetros sanguíneos de vacas leiteiras alimentadas com diferentes níveis de grão de soja cru e integral nas rações. Arch Zootec, 61: 483492.

Bremmer, D.R.; Ruppert, L.D. and Clark, J.H. 1998. Effects of chain length and instauration of fatty acid mixtures infused into the abomasum of lactating dairy cows. J Dairy Sci, 81: 176-188.

Christensen, R.A.; Cameron, M.R.; Clark, J.H.; Drackley, J.K.; Lynch, J.M. and Barbano, D.M. 1994. Effects of amount of protein and ruminally protected amino acids in the diet of dairy cows fed supplemental fat. J Dairy Sci, 77: 16181629.

Corrêa, A.M.V. 2007. Utilização de grão de soja em diferentes formas na alimentação de vacas leiteiras. Tese (Doutorado em Zootecnia). Universidade Federal Viçosa. Minas Gerais. Viçosa. $128 \mathrm{f}$.

Deresz, F.; Fernandes, A.M. e Matos, L.L. 1996. Utilização da soja-grão crua na alimentação de desempenho produtivo de vacas leiteiras no terço médio de lactação, sendo recomendado o uso do grão de soja cru inteiro nas dietas de vacas leiteiras.

\section{AGRADECIMENTOS}

Ao Conselho Nacional de Desenvolvimento Cientifico e Tecnológico (CNPq), pela concessão da bolsa de estudo, que gerou tranquilidade e possibilitou a dedicação intensa e exclusiva a este trabalho.

À Fundação de Amparo à Pesquisa do Estado de São Paulo-FAPESP, pela concessão de auxílio à pesquisa que possibilitou a realização deste estudo.

Ao Laboratório de Pesquisa em Bovinos de Leite (LPBL) da Faculdade de Medicina Veterinária e Zootecnia (FMVZ) da Universidade de São Paulo.

vacas leiteiras de alta produção. Rev Bras Zootecn, 25: 113-124.

Dhiman, T.R.; Nam, S.H. and Ure, A.L. 2005. Factors affecting conjugated linoleic acid content in milk and meat. Crit Rev Food Sci, 45: 463-482.

Elliott, J.P.; Drackley, J.K.; Schauff, D.J. and Jaster, E.H. 1993. Diets containing high oil corn and tallow for dairy cows during early lactation. $J$ Dairy Sci, 76: 775-789.

Hall, M.B. 1998. Making nutritional sense of nonstructural carboidrates. In: Annual Florida Ruminant Nutrition Symposium, 9. Gainsville, F1. Proceedings... Florida University. Gainsville. pp. 108-121.

Hoedemaker, M.; Prange, D.; Zerbe, H.; Frank, J.; Daxenberger, A. and Meyer, H.H.D. 2004. Peripartal propylene glycol supplementation and metabolism, animal health, fertility, and production in dairy cows. J Dairy Sci, 87: 2136-2145.

Kaneko, J.J.; Harvey, J.W. and Bruss, M. 1997. Appendices. In: Kaneko, J.J; Harvey, J.W; Bruss, M. Clinical biochemistry of domestic animals. $5^{\text {th }}$ ed. Academic PR. San Diego. pp. 885-905.

McDonald, P.M.; Edwards, R.A.; Greenhalgh, J.F.D.; Morgan, C.A. 2002. Animal nutritition. Harlow. 


\section{NAVES ETAL.}

Pearson. UK. 693 pp.

Mohamed, O.E.; Satter, L.D. and Grummer, R.R. 1988. Influence of dietary cottonseed and soybeans on milk production and composition. J Dairy Sci, 71: 2677-2687.

NRC. 2001. National Research Council. Nutrient Requirements of dairy cattle. $7^{\text {a }}$ ed. National Academic Press. Washinton, D.C. 381 pp.

Oliveira, N.J.F.; Melo, M.M.; Lago, L.A. e Nascimento, E.F. 2005. Hemograma, bioquímica sérica e histologia da biópsia hepática de bovinos após administração de polpa cítrica. Arq Bras Med Vet Zoo, 57: 418-422.

Rabello, T.M.; Valadares Filho, S.C. e Coelho da Silva, J.F. 1996. Grão de soja moído na alimentação de vacas em lactação. Consumo, produção e composição do leite. Rev Bras Zootecn, 25: 345-356.

Roseler, D.K.; Fergnson, J.D.; Sniffen, C.J. and Herrema, J. 1993. Dietary protein degradability effects on plasma and milk urea nitrogen and milk nonprotein nitrogen in holstein cows. $J$
Dairy Sci, 76: 525-534.

SAS. 2004. SAS, version 9.1.3, SAS Institute Inc. Cary, NC. USA

Schauff, D.J.; Elliot, J.P.; Clark, J.H. and Drackley, J.K. 1992. Effects of feeding lactating dairy cows diets containing whole soybeans and tallow. J Dairy Sci, 75: 1923-1935.

Sklan, D.; Ashkenazi, R.; Brun, A.; Devorin, A. and Tabori, K. 1992. Fatty acids, calcium soaps of fatty acids, and cottonseeds fed to high yielding cows. J Dairy Sci, 75: 2463-2472.

Sniffen, C.J.; O'Connor, J.D. and Van Soest, P.S. 1992. A net carbohydrate and protein system for evaluating cattle diets. ii. carbohydrate and protein availability. J Anim Sci, 70: 3562-3577.

Van Soest, P.J. and Mason, V.C. 1991. The influence of maillard reaction upon the nutritive value of fibrous feeds. Anim Feed Sci Tech, 32: 45-53.

Weiss, W.P.; Conrad, H.R. and Pierre, N.R.S.T 1992. A theoretically-based model for predicting total digestible nutrient values of forages and concentrates. Anim Feed Sci Tech, 39: 95-110.

Archivos de zootecnia vol. 62, núm. 240, p. 588. 